\title{
Public health impact and cost-effectiveness of dairy products supplemented with vitamin $D$ in prevention of osteoporotic fractures
}

\author{
Olivier Ethgen ${ }^{1}$, Mickaël Hiligsmann ${ }^{2}$, Nansa Burlet ${ }^{3}$ and Jean-Yves Reginster ${ }^{4}$
}

\begin{abstract}
Background: Dietary sources of calcium and vitamin D are recommended as a first-line strategy in prevention of osteoporosis-related fractures but their public health and economic impact has never been studied.

Methods: We designed a population-based model to forecast the potential health outcomes and medical effectiveness of the daily administration of dairy supplements containing $800 \mathrm{IU}$ of vitamin $\mathrm{D}$ and $1 \mathrm{~g}$ of calcium in cohorts of subjects, from both genders, aged 50, 60, 70 and 80 years. Annual costs of dairy products were tested at $€ 150, € 250$ and $€ 350$.

Results: In total, the daily intake of vitamin-D rich dairy products reduces by 30,376 and 16,105 events the number of osteoporotic fractures in women and men respectively and permits to gain 6605 and 6144 life-years, in women and men respectively. This intervention is cost-effective from 70 years on in the general population and from 60 years on in patients at increased risk of osteoporotic fractures.

Conclusion: The recommendation to use dairy products as the preferred source of calcium and vitamin D in aging males and females is supported by public health and health economic analyses.
\end{abstract}

Keywords: Osteoporosis, Cost-effectiveness, Dairy products, Vitamin D, Fracture, Osteoporosis

\section{Background}

Osteoporosis (OP) is defined as a systemic disease characterized by low bone mass and microarchitectural deterioration of bone tissue, with a consequent increase in bone fragility and susceptibility to fractures $(\mathrm{Fx})[1,2]$. Collectively, all OP Fx account for 2.7 million Fx in men and women in Europe [2]. In 2010, the direct costs of $\mathrm{OP} F \mathrm{Fx}$ in the five largest EU countries was evaluated at $€ 29$ billion and at $€ 38.7$ billion in the 27 countries [3, 4]. All OP Fx but forearm are associated with increased mortality [5, 6]. In 2012, the number of deaths causally related to OP Fx in the European union, was estimated at 43,000 [4], of which $50 \%$ were due to hip Fx, $28 \%$ to clinical vertebral and $22 \%$ to other Fx [2]. This high societal and personal burden poses challenges to public health and physicians [2]. There is a high prevalence of vitamin $\mathrm{D}$ insufficiency in the elderly and dietary

\footnotetext{
*Correspondence: jyreginster@ulg.ac.be

${ }^{4}$ Department of Public Health, Epidemiology and Health Economics,

University of Liege, Liege, Belgium

Full list of author information is available at the end of the article
}

calcium is low in many postmenopausal OP women [7-10], notwithstanding most data suggest that dietary intakes of key bone nutrients such as calcium, vitamin $\mathrm{D}$ and proteins contribute to bone health and reduce the risk of Fx later in life [2, 11]. Dietary sources of nutrients are the preferred option and pharmacological supplementation should only be targeted to those individuals who do not get sufficient calcium from their diet and who are at increased risk for OP [2]. Recent European consensus recommend adequate vitamin $\mathrm{D}$ intake of $800 \mathrm{IU} /$ day as well as calcium intake of $1000 \mathrm{mg} /$ day $[7,12]$. Until now, few studies targeted the cost-effectiveness of calcium and vitamin D supplementation in OP $[13,14]$ and even less [15] assessed the public health and economic impact of fortified dairy products given to the general elderly population.

\section{Methods}

We designed a population-based model to forecast and compare the potential population health outcomes and medical costs following an appropriate daily intake of 
calcium/vitamin D in Belgium. Appropriate daily intake was obtained by the administration, on top of the regular diet, of a daily dairy supplementation containing $1000 \mathrm{mg}$ of calcium and $800 \mathrm{IU}$ of vitamin D [7, 12]. This amount can be achieved with $1 \mathrm{l}$ of milk (35 g of proteins), $100 \mathrm{~g}$ of Comte cheese ( $28 \mathrm{~g}$ proteins) or 4 yogurts ( $20 \mathrm{~g}$ of proteins). The model was actually an extension of an extensively published and validated cost-effectiveness microsimulation model of OP management [13, 16-18]. The model was reengineered to accommodate multiple age cohorts, constituent of a population [19].

We used the median variant population projection 2014-2060 from the SPF Economie, the official source for socio-demographic data in Belgium [20, 21]. Projections for 4 female and 4 male cohorts aged 50, 60, 70 and 80 years on the 1st of January 2015 were extracted (birth cohorts 1965, 1955, 1945 and 1935).

The 8 cohorts were stratified according to their baseline risk of OP Fx: general population, population with osteoporosis (as defined by a BMD T-score $\leq 2.5$ ) and population with a prevalent vertebral or hip Fx. Baseline prevalence estimates per age were derived from literature [3]. Prevalence assumptions and resulting numbers of individuals with OP and a prevalent hip or vertebral Fx in age strata are presented in Tables 1 and 2.

In the model, the occurrence of Fx at individual ages is modelled through a health-state transition process (Markov model). Individuals begin either in the general population within the non-Fx state, in the OP population within the non-Fx state or in the OP population within the prevalent Fx state. Individuals then progress according to their baseline characteristics and agespecific Fx risk through the non-Fx stage, hip Fx stage, vertebral Fx stage, wrist Fx stage or other Fx stage.

As it is a population-based model, the size of each cohort corresponds to the actual size of the corresponding age cohort in the Belgian population. Hence, the adapted model differs from the previous microsimulation model on the target population dynamics as it does not assume a hypothetical and microsimulated cohort of patients

Table 1 Prevalence of osteoporosis and vertebral/hip fracture in 4 birth cohorts of women

\begin{tabular}{|c|c|c|c|c|c|c|c|}
\hline \multirow[t]{2}{*}{ Age } & \multirow[t]{2}{*}{ Total $^{a}$} & \multicolumn{2}{|l|}{ General } & \multicolumn{2}{|c|}{ Osteoporosis $^{b}$} & \multicolumn{2}{|c|}{ Prevalent fracture } \\
\hline & & $\%$ & $\mathrm{~N}$ & $\%$ & $\mathrm{~N}$ & $\%$ & $\mathrm{~N}$ \\
\hline 50 & 83,691 & $93.3 \%$ & 78,084 & $6.6 \%$ & 5524 & $0.1 \%$ & 84 \\
\hline 60 & 7 & 8 & 5 & $\%$ & 0 & $1.8 \%$ & 1278 \\
\hline 70 & 52,754 & $67.0 \%$ & 35,345 & $28.6 \%$ & 15,08 & $84.4 \%$ & 2321 \\
\hline 80 & 41,157 & $40.1 \%$ & 16,504 & $47.2 \%$ & 19,426 & $12.7 \%$ & 5,2271 \\
\hline
\end{tabular}

${ }^{\mathrm{a} S P F}$ Economie. Ref. 20-21

${ }^{\mathrm{b}} \mathrm{BMD}$ T-Score $\leq 2.5$. Ref. 22

'Prevalent hip or vertebral Fx. Ref 22
Table 2 Prevalence of osteoporosis and vertebral/hip fracture in 4 birth cohorts of men

\begin{tabular}{|c|c|c|c|c|c|c|c|}
\hline \multirow[t]{2}{*}{ Age } & \multirow[t]{2}{*}{ Total $^{a}$} & \multicolumn{2}{|l|}{ General } & \multicolumn{2}{|c|}{ Osteoporosis ${ }^{\mathrm{b}}$} & \multicolumn{2}{|c|}{ Prevalent fracture } \\
\hline & & $\%$ & $\mathrm{~N}$ & $\%$ & $\mathrm{~N}$ & $\%$ & $\mathrm{~N}$ \\
\hline 50 & 85,138 & $97.2 \%$ & 82,754 & $2.6 \%$ & 2214 & $0.2 \%$ & 170 \\
\hline 60 & 69,040 & $91.9 \%$ & 63,448 & $6.7 \%$ & 4626 & $1.4 \%$ & 967 \\
\hline 70 & 47,455 & $88.5 \%$ & 41,998 & $8.5 \%$ & 4034 & $3.0 \%$ & 1424 \\
\hline 80 & 29,235 & $57.0 \%$ & 16,664 & $36.0 \%$ & 10,525 & $7.0 \%$ & 2046 \\
\hline
\end{tabular}

${ }^{\mathrm{a} S P F}$ Economie. Ref. 20-21

${ }^{\mathrm{b}} \mathrm{BMD} \mathrm{T}$-Score $\leq 2.5$. Ref. 22

'Prevalent hip or vertebral Fx. Ref 22

but projects the impact of calcium/vitamin D supplementation, through dairy products, on a specific age cohort over its respective remaining lifetime. All transition probabilities were recalculated as annual transition probabilities as the original microsimulation model uses 6month probabilities.

Each year, all individuals can die from age-specific background mortality from any health state.

As for the population size estimates above, the agespecific background mortality rates were taken from the SPF Economie [20, 21]. We assumed that hip Fx increased death probabilities by 5.5 , as evidenced in a meta-analysis [22]. The same excess mortality was assumed for vertebral Fx but not for wrist and others Fx.

The risk of hip Fx was derived from the Belgian national database of hospital bills [23]. Since the incidence of non-hip Fx was not known, we applied the agespecific ratio of index Fx to hip Fx in Belgium as found in Sweden [24]. All estimates were interpolated using exponential regression to obtain age-specific risk of Fx. We assumed an increased risk of $\mathrm{Fx}$ for individuals who had a prior $\mathrm{Fx}$ at the same location. These increased relative risks were 2.3, 4.4, 3.3 and 1.9 for hip, vertebral, wrist and others Fx, respectively [16, 25, 26].

Calcium/vitamin D supplementation effectiveness in the reduction of $\mathrm{Fx}$ incidence was taken from a recent study [13] that reviewed and synthesized metaanalyses previously published on the subject. Calcium/vitamin D supplementation has been shown to reduce the risk of hip Fx by $18 \%(R R=0.8295 \%$ CI:[7.1-0.94] in a meta-analysis of 6 trials including 45.509 patients) [27], the risk of vertebral Fx by $13 \%$ $(R R=0.8795 \% \mathrm{Cl}:[0.75-1.01]$ in a meta-analysis including 45.164 patients) [28] and the risk of non-hip non-vertebral Fx by $20 \%(R R=0.8095 \% \mathrm{Cl}:[0.72-$ 0.89 ] in a meta-analysis of 9 trials including 32.285 patients) [29]. Patients were assumed to follow calcium/vitamin D supplementation for their remaining lifetime. The protective effect of calcium/vitamin D supplementation on Fx risk was thus assumed to remain constant over time. 
The perspective for the cost calculation is that of the Belgian health care payers (government and patients) as recommended in the Belgian pharmacoeconomics guideline [30]. Only direct medical costs were taken into account. The hospitalization cost of hip Fx was retrieved from the Belgian national database of hospital bills for the year 2007 [13, 17, 18]. Extra costs in the year following a hip Fx were derived from a prospective study of 159 women [31]. The costs of non-hip Fx were estimated relative to hip Fx [32]. We assumed that non-hip Fx were not associated with long-term costs. As for the risks of $\mathrm{Fx}$, all cost estimates were interpolated using power or polynomial regression to obtain age-specific cost of Fx. In the absence of official pricing data, as opposed to pharmaceutical for instance, the price of the supplementation with dairy products was derived from the observed market price of vitamin D-enriched milk and yogurt and was assumed at $€ 250$ per year and tested between $€ 150$ and $€ 350$. All costs were expressed in $€ 2014$ using the national health price index $[20,21]$ and were discounted at $3 \%$ per annum.

The model has a lifetime horizon for each age cohort considered.

We projected the number of Fx avoided and life-years gained (LYG) for each age cohort, from 50 to 80 years of age in 2015 (born between 1935 and 1965). We also computed the cost-per-Fx avoided and the cost-per-LYG for each age cohort.

\section{Results}

Tables 3 and 4 summarize the projected health and cost impacts of the recommended dairy daily intake versus the absence of appropriate intake for women and men aged 50, 60, 70 and 80 years in 2015 in Belgium. In total, 30,376 Fx would be avoided and 6605 LY would be gained in the 4 age cohorts of women over their remaining lifetime. In men, the number of Fx avoided and LYG amounted 16,105 and 6144, respectively. The greatest absolute gains were seen in the general population segment, regardless of gender of baseline age.

The cost-per-Fx avoided was below $€ 60,000$ in women (maximum of $€ 55,524$ in the general population aged 50 years with a cost of supplementation at $€ 350$ per year) and below $€ 90,000$ in men (maximum of $€ 86,463$ in the general population aged 50 years with a cost of supplementation at $€ 350$ per year). In both gender, the cost-per-Fx avoided declined markedly with age and baseline risk of Fx.

The cost-per-LYG (cost-effectiveness) was above $€ 100,000$ in the 50 years age cohort for both women and men, except in the prevalent Fx risk-group. The cost-per-LYG declined along aging cohorts and in the older cohort (80 years), the cost-per-LYG generally fell below $€ 50,000$. In all instances, the cost-per-LYG tended to be more favorable (i.e. lower) in older and riskier cohorts.

Detailed results for each specific age cohort of women and men are presented as Additional file 1.

\section{Discussion}

Our study suggest that by ensuring an adequate repletion in calcium and vitamin D to the general population, by the administration of dairy products providing $800 \mathrm{IU}$ of vitamin D and $1000 \mathrm{mg}$ of calcium daily, it is possible to reduce the number of OP-related FX and to provide a substantial number of LYG, in people for both genders, currently aged from 50 to 80 years old. Our results also suggest that this intervention is cost/effective in both genders, above the age of 70 years in the general population and from 60 years and above in subjects at increased risk of OP. Although, the clinical efficacy of pharmacological or non-pharmacological interventions may be consistent across settings, their impact on public health or their economic value may differ, owing to differences in epidemiologic variations, interventionsrelated costs and effectiveness of available alternative strategies [33, 34]. In Europe, OP accounts for more disability and LY lost than all other major musculoskeletal conditions, except osteoarthritis but including rheumatoid arthritis [2]. With regards to neoplastic diseases, the burden of OP is greater than all sites of cancer with the exception of lung cancer [35]. Several studies assessed the efficacy and efficiency of pharmacological interventions in OP [36]. However, nutritional interventions whereas considered as first-line measures in most guidelines dedicated to the management of $\mathrm{OP}[1,2,7,12]$ are less frequently studied in terms of their impact on public health or health resources utilization [15]. This study is the first to apply a validated cost-effectiveness microsimulation model [16], adapted to a public health perspective [19] to the outcomes of calcium and vitamin $\mathrm{D}$ administration, as dairy products, on reduction of $\mathrm{Fx}$ or on gain in LY and to determine whether such an intervention may be considered cost-effective in the general population and in individuals at increased risk of OP-related Fx. The scarcity of available resources and the increasing demand for healthcare require more rational assignment of resources and better definition of priorities. In this scenario, economic evaluations provide valuable information and LYG is widely recognized as an appropriate outcome [37]. Our results show that vitamin D-enriched dairy products, given to the general population, from the age of 50 years can spare more than 30,000 OP Fx in women and more than 15,000 OP Fx in men and save more than $6600 \mathrm{LY}$ in women and more than $6100 \mathrm{LY}$ in men. As expected, the cost-effectiveness of dairy product administration in OP, as it is the case for any intervention, is strongly influenced by the cost of 
Table 3 Health and cost impact of recommended CANit D dietary intake in women

\begin{tabular}{|c|c|c|c|c|c|c|c|c|}
\hline \multirow[t]{2}{*}{ Fracture avoided } & \multicolumn{8}{|l|}{ LYG } \\
\hline & $50 y$ & $60 y$ & $70 y$ & $80 y$ & $50 y$ & $60 y$ & $70 y$ & $80 y$ \\
\hline General & 9928 & 6739 & 3497 & 1219 & 1305 & 1242 & 1040 & 706 \\
\hline Osteoporosis1 & 1051 & 1967 & 2131 & 1944 & 86 & 240 & 472 & 991 \\
\hline Prevalent fracture2 & 29 & 406 & 594 & 871 & 2 & 38 & 97 & 386 \\
\hline \multirow[t]{2}{*}{ Cost per fracture avoided } & \multicolumn{8}{|c|}{ Cost per LYG } \\
\hline & $50 y$ & $60 y$ & $70 y$ & $80 y$ & $50 y$ & $60 y$ & $70 y$ & $80 y$ \\
\hline \multicolumn{9}{|l|}{ General } \\
\hline Ca/Nit.D €150/year & $€ 22,462$ & $€ 19,094$ & $€ 14,467$ & $€ 8064$ & $€ 170,818$ & $€ 103,630$ & $€ 48,663$ & $€ 13,924$ \\
\hline Ca/Nit.D €250/year & $€ 38,993$ & $€ 33,990$ & $€ 27,182$ & $€ 17,815$ & $€ 296,532$ & $€ 184,479$ & $€ 91,430$ & $€ 30,759$ \\
\hline Ca/Vit.D €350/year & $€ 55,524$ & $€ 48,887$ & $€ 39,896$ & $€ 27,566$ & $€ 422,245$ & $€ 265,329$ & $€ 134,197$ & $€ 47,594$ \\
\hline \multicolumn{9}{|l|}{ Osteoporosis $^{a}$} \\
\hline Ca/Nit.D €150/year & $€ 13,617$ & $€ 11,144$ & $€ 7690$ & $€ 3057$ & $€ 165,846$ & $€ 91,326$ & $€ 34,719$ & $€ 5997$ \\
\hline Ca/Nit.D $€ 250 /$ year & $€ 24,655$ & $€ 21,277$ & $€ 16,547$ & $€ 10,149$ & $€ 300,277$ & $€ 174,359$ & $€ 74,707$ & $€ 19,910$ \\
\hline CaNit.D €350/year & $€ 35,692$ & $€ 31,409$ & $€ 25,404$ & $€ 17,240$ & $€ 434,709$ & $€ 257,392$ & $€ 114,696$ & $€ 33,822$ \\
\hline \multicolumn{9}{|l|}{ Prevalent fracture ${ }^{b}$} \\
\hline CaNit.D €150/year & $€ 5941$ & $€ 3711$ & $€ 1049$ & $€ 0$ & $€ 83,603$ & $€ 39,497$ & $€ 6392$ & $€ 0$ \\
\hline Ca/Nit.D $€ 250 /$ year & $€ 11,988$ & $€ 9090$ & $€ 5856$ & $€ 1492$ & $€ 168,701$ & $€ 96,744$ & $€ 35,687$ & $€ 3369$ \\
\hline Ca/Nit.D $€ 350 /$ year & $€ 18,035$ & $€ 14,469$ & $€ 10,663$ & $€ 5532$ & $€ 253,799$ & $€ 153,992$ & $€ 64,982$ & $€ 12,493$ \\
\hline
\end{tabular}

${ }^{\mathrm{a} B M D}$ T-score $\leq 2.5$

${ }^{\mathrm{b}} \mathrm{Hip}$ or vertebral

Table 4 Health and cost impact of recommended CANit D dietary intake in men

\begin{tabular}{|c|c|c|c|c|c|c|c|c|}
\hline & \multicolumn{4}{|c|}{ Fracture avoided } & \multicolumn{4}{|l|}{ LYG } \\
\hline & $50 y$ & $60 y$ & $70 y$ & $80 y$ & $50 y$ & $60 y$ & $70 y$ & $80 y$ \\
\hline General & 6383 & 4315 & 2351 & 675 & 1727 & 1540 & 1216 & 571 \\
\hline Osteoporosis ${ }^{\mathrm{a}}$ & 279 & 498 & 342 & 601 & 49 & 131 & 149 & 479 \\
\hline \multirow[t]{3}{*}{ Prevalent fracture ${ }^{b}$} & 40 & 195 & 223 & 203 & 6 & 41 & 80 & 155 \\
\hline & \multicolumn{4}{|c|}{ Cost per fracture avoided } & \multicolumn{4}{|c|}{ Cost per LYG } \\
\hline & $50 y$ & $60 y$ & $70 y$ & $80 y$ & $50 y$ & $60 y$ & $70 y$ & $80 y$ \\
\hline \multicolumn{9}{|l|}{ General } \\
\hline Ca/Nit.D €150/year & $€ 35,684$ & $€ 31,117$ & $€ 24,794$ & $€ 16,389$ & $€ 131,903$ & $€ 87,190$ & $€ 47,950$ & $€ 19,377$ \\
\hline CaNit.D €250/year & $€ 61,073$ & $€ 54,030$ & $€ 44,275$ & $€ 31,334$ & $€ 225,753$ & $€ 151,392$ & $€ 85,627$ & $€ 37,048$ \\
\hline CaNit.D €350/year & $€ 86,463$ & $€ 76,943$ & $€ 63,757$ & $€ 46,279$ & $€ 319,603$ & $€ 215,595$ & $€ 123,304$ & $€ 54,719$ \\
\hline \multicolumn{9}{|l|}{ Osteoporosis ${ }^{a}$} \\
\hline Ca/Vit.D €150/year & $€ 20,250$ & $€ 17,654$ & $€ 13,935$ & $€ 8873$ & $€ 115,310$ & $€ 66,932$ & $€ 32,000$ & $€ 11,124$ \\
\hline Ca/Nit.D €250/year & $€ 35,749$ & $€ 32,068$ & $€ 26,716$ & $€ 19,327$ & $€ 203,563$ & $€ 121,582$ & $€ 61,349$ & $€ 24,231$ \\
\hline CaNit.D €350/year & $€ 51,248$ & $€ 46,482$ & $€ 39,497$ & $€ 29,781$ & $€ 291,816$ & $€ 176,231$ & $€ 90,697$ & $€ 37,337$ \\
\hline \multicolumn{9}{|l|}{ Prevalent fracture ${ }^{b}$} \\
\hline CaNit.D €150/year & $€ 9214$ & $€ 7204$ & $€ 4546$ & $€ 1148$ & $€ 62,625$ & $€ 34,065$ & $€ 12,649$ & $€ 1505$ \\
\hline Ca/Nit.D €250/year & $€ 17,483$ & $€ 14,815$ & $€ 11,293$ & $€ 6799$ & $€ 118,823$ & $€ 70,057$ & $€ 31,423$ & $€ 8916$ \\
\hline CaNit.D €350/year & $€ 25,751$ & $€ 22,427$ & $€ 18,040$ & $€ 12,451$ & $€ 175,022$ & $€ 106,049$ & $€ 50,197$ & $€ 16,327$ \\
\hline
\end{tabular}


the intervention and by the risk profile of the subject. No standard for upper threshold of cost per LYG, that would constitute an absolute value of the critical costeffectiveness ratio, is explicitly fixed [38]. However, tentative guidelines place it in the range of $\$ 20,000$ to $\$ 100,000$ per LYG [39], while other authors consider that up to $\$ 166,000$ per LYG, cost-efficiency is debatable [40].

The World Health Organization (WHO) suggests that interventions with a cost-effectiveness ratio between 1 and 3-fold de Gross Domestic Product (GDP) per capita of the country where the study is conducted are cost/ effective [41]. In Belgium, GDP per capita accounted $€ 37,857.75$ in 2014. These figures, based on the WHO recommendations [41] suggest that cost-effective ratios below $€ 120,000 /$ LYG are acceptable.

The cost-effectiveness ratio of our intervention remains below or around $€ 100,000 / \mathrm{LYG}$ in the general population at 70 years and above, while these values are observed from 60 years on, in subjects at increased risk of OP Fx except in the sensitivity analysis setting up the price of the dairy intervention at $€ 350$ /year.

Like any health economic study, our work is based on a number of assumptions. The cost-effectiveness is critically dependent on the evidence for efficacy of the intervention. It could be argued that prospective, randomized controlled studies establishing the anti Fx efficacy of dairy product are currently missing [42]. Some cohort studies also generated unconclusive evidence on reduction of Fx following milk intake. However, these cohorts did not use any vitamin D-enriched dairy products [43-46], while our analysis is based on the intake of dairy products providing the amount of calcium and vitamin $\mathrm{D}$, which are considered by most experts and recommendations from scientific organizations as appropriate to improve bone health [1, 2, 7, 12]. Divergent opinion, challenging the interest of calcium and vitamin D in OP [47] or reporting putative increase in adverse effects following calcium supplementation [48] appear to be insufficiently substantiated [49] and, at any rate more directed towards calcium pharmacological supplementation than against dairy products intake [48].

Our extrapolation of the anti-Fx efficacy obtained with pharmacological supplementation of calcium and vitamin $\mathrm{D}$ to dairy products providing the same amount of nutrients is indeed likely to be highly conservative. Several studies have documented the link between low intake of dairy foods and decreased bone mineral density or increased Fx risk [50, 51].

At every stage of life, adequate dietary intake of key bone nutrients including not only calcium and vitamin D but also proteins contributes to muscle and bone health, thereby reducing the risk of falls, OP and Fx later in life [12]. Dairy products are rich in proteins [52]. There is no clear-cut evidence that individuals aged more than 50 years old have a deficit in protein intake similar to what is reported for calcium and vitamin D [53]. However, it is possible that our analysis, based only on the beneficial effects of calcium and vitamin D on bone, without modelling the potential benefits of proteins underestimates the positive outcomes of dairy products intake.

Furthermore, it is well known that the efficacy of anti OP medications, including pharmacological supplements of calcium and vitamin D is decreased as a result of poor adherence [54]. The impact of low compliance and persistence on the cost-effectiveness of these treatments is well documented [55]. Dairy food has been shown to be an appropriate vehicle to provide calcium, with good compliance compared to pharmacological supplements $[15,56]$, which might have a positive effect on the effectiveness of our approach. This might also be emphasized because the putative deleterious effect of pharmacological calcium supplementation on myocardial infarction was never reported following dairy products intake. Eventually, different studies showed that calcium and vitamin D supplementation have other health benefits effects. So, studies suggested that calcium and vitamin D may reduce the risk for breast cancer mainly in premenopausal women [57] and colon cancer in older women [58]. A meta-analysis has also indicated that vitamin D may have a small beneficial effect on cardiovascular risk and mortality [59].

All these potential benefits might increase the number of LYG by our dairy product supplementation and, subsequently, improve the cost/effectiveness of the intervention by reducing the cost/LYG. Eventually, we only assessed beneficial outcomes generated by the calcium/ vitamin D supplementation in terms of LYG. Improvements in quality of life and subsequent quality-adjusted LY were also reported following the Fx risk reduction induced by a dietary supplementation in calcium/vitamin $\mathrm{D}$ and reflect a qualitative benefit that is superimposed to the quantitative outcome assessed by the LYG.

\section{Conclusion}

Dietary sources of nutrients are recommended as appropriate to ensure adequate calcium and vitamin D repletion. This recommendation, widely claimed to be justified in terms of efficacy is also supported by our public health impact and health economics analyses.

\section{Additional file}

Additional file 1: Results in women and men. (PDF $212 \mathrm{~kb}$ )

\section{Abbreviations}

BMD: Bone mineral density; Fx: Facture; GDP: Gross domestic product; LYG: Life-years gained; LY: Life-years; OP: Osteoporosis; WHO: World Health Organization. 


\section{Competing interests}

Olivier Ethgen has no relevant competing interests to declare.

Mickael Hiligsmann has received research grant and/or consulting fees from Amgen, Pfizer, Novartis, Servier and SMB.

Nansa Burlet has no relevant competing interests to declare.

Jean-Yves Reginster has received research grant and/or consulting fees from Servier, Novartis, Negma, Lilly, Wyeth, Amgen, GlaxoSmithKline, Roche, Merckle, Nycomed-Takeda, NPS, IBSA-Genevrier, Theramex, UCB, Asahi Kasei, Endocyte, Merck Sharp and Dohme, Rottapharm, Teijin, Teva, Analis, NovoNordisk, Ebewee Pharma, Zodiac, Danone, Will Pharma, Meda, Bristol Myers Squibb, Pfizer, Organon, Therabel, Boehringer, Chiltern, Galapagos.

\section{Authors' contributions}

$\mathrm{MH}$ developed the original pharmaco-economic model and OE adapted it to a public health perspective. JYR, NB and OE designed the study. OE was responsible for running the model. JYR and NB drafted the manuscript which was reviewed by $\mathrm{MH}$ and $\mathrm{OE}$. All authors read and approved the final manuscript.

\section{Acknowledgment}

The authors would like to thanks Mrs Strauven for her secretarial assistance in the preparation of the manuscript.

\section{Funding}

This manuscript has not funded by any third party and was fully supported by the Department of public Health Sciences, University of Liège, Liège-Belgium.

\section{Author details}

${ }^{1}$ Department of Public Health, Epidemiology and Health Economics, University of Liege, Liege, Belgium. ²Department of Health Services Research, Maastricht University, Maastricht, The Netherlands. ${ }^{3}$ Department of Public Health, Epidemiology and Health Economics, University of Liege, Liege, Belgium. ${ }^{4}$ Department of Public Health, Epidemiology and Health Economics, University of Liege, Liege, Belgium.

\section{Received: 9 September 2015 Accepted: 24 September 2015} Published online: 14 December 2015

\section{References}

1. Kanis JA, Delmas P, Burckhardt P, Cooper C, Torgerson D. Guidelines for diagnosis and management of osteoporosis. The European Foundation for Osteoporosis and Bone Disease. Osteoporos Int 1997;7(4):390-406.

2. Kanis JA, McCloskey EV, Johansson H, Cooper C, Rizzoli R, Reginster JY, et al. European guidance for the diagnosis and management of osteoporosis in postmenopausal women. Osteoporos Int. 2013;24(1):23-57. doi:10.1007/ s00198-012-2074-y.

3. Svedbom A, Hernlund E, Ivergard M, Compston J, Cooper C, Stenmark J, et al. Osteoporosis in the European Union: a compendium of country-specific reports. Arch Osteoporos. 2013;8:137. doi:10.1007/s11657-013-0137-0.

4. Strom O, Borgstrom F, Kanis JA, Compston J, Cooper C, McCloskey EV, et al. Osteoporosis: burden, health care provision and opportunities in the EU: a report prepared in collaboration with the International Osteoporosis Foundation (IOF) and the European Federation of Pharmaceutical Industry Associations (EFPIA). Arch Osteoporos. 2011;6:59-155. doi:10.1007/s11657-011-0060-1.

5. Hernlund E, Svedbom A, Ivergard M, Compston J, Cooper C, Stenmark J, et al. Osteoporosis in the European Union: medical management, epidemiology and economic burden. A report prepared in collaboration with the International Osteoporosis Foundation (IOF) and the European Federation of Pharmaceutical Industry Associations (EFPIA). Arch Osteoporos. 2013;8:136. doi:10.1007/s11657-013-0136-1.

6. Cooper C, Atkinson EJ, Jacobsen SJ, O'Fallon WM, Melton 3rd LJ. Populationbased study of survival after osteoporotic fractures. Am J Epidemiol. 1993;137(9):1001-5.

7. Rizzoli R, Boonen S, Brandi ML, Bruyere O, Cooper C, Kanis JA, et al. Vitamin D supplementation in elderly or postmenopausal women: a 2013 update of the 2008 recommendations from the European Society for Clinical and Economic Aspects of Osteoporosis and Osteoarthritis (ESCEO). Curr Med Res Opin. 2013;29(4):305-13. doi:10.1185/03007995.2013.766162.
8. Bruyere O, Slomian J, Beaudart C, Buckinx F, Cavalier E, Gillain S, et al. Prevalence of vitamin $D$ inadequacy in European women aged over 80 years. Arch Gerontol Geriatr. 2014;59(1):78-82. doi:10.1016/ j.archger.2014.03.010.

9. Bruyere O, Malaise O, Neuprez A, Collette J, Reginster JY. Prevalence of vitamin D inadequacy in European postmenopausal women. Curr Med Res Opin. 2007;23(8):1939-44. doi:10.1185/030079907X219562.

10. Bruyere O, De Cock C, Mottet C, Neuprez A, Malaise O, Reginster JY. Low dietary calcium in European postmenopausal osteoporotic women. Public Health Nutr. 2009;12(1):111-4. doi:10.1017/S1368980008002024.

11. Bruyere O, Cavalier E, Souberbielle JC, Bischoff-Ferrari HA, Beaudart C, Buckinx $F$, et al. Effects of vitamin D in the elderly population: current status and perspectives. Arch Public Health. 2014;72(1):32. doi:10.1186/ 2049-3258-72-32.

12. Rizzoli R, Stevenson JC, Bauer JM, van Loon $\amalg$, Walrand S, Kanis JA, et al. The role of dietary protein and vitamin $\mathrm{D}$ in maintaining musculoskeletal health in postmenopausal women: a consensus statement from the European Society for Clinical and Economic Aspects of Osteoporosis and Osteoarthritis (ESCEO). Maturitas. 2014;79(1):122-32. doi:10.1016/ j.maturitas.2014.07.005.

13. Hiligsmann M, Ben Sedrine W, Bruyere O, Evers SM, Rabenda V, Reginster JY. Cost-effectiveness of vitamin D and calcium supplementation in the treatment of elderly women and men with osteoporosis. Eur J Pub Health. 2015;25(1):20-5. doi:10.1093/eurpub/cku119.

14. Reginster JY. Calcium and vitamin D for osteoporotic fracture risk. Lancet. 2007;370(9588):632-4. doi:10.1016/S0140-6736(07)61315-4.

15. Lotters FJ, Lenoir-Wijnkoop I, Fardellone P, Rizzoli R, Rocher E, Poley MJ. Dairy foods and osteoporosis: an example of assessing the health-economic impact of food products. Osteoporos Int. 2013;24(1):139-50. doi:10.1007/ s00198-012-1998-6.

16. Hiligsmann M, Ethgen O, Bruyere O, Richy F, Gathon HJ, Reginster JY. Development and validation of a Markov microsimulation model for the economic evaluation of treatments in osteoporosis. Value Health. 2009;12(5):687-96. doi:10.1111/j.1524-4733.2008.00497.x.

17. Hiligsmann M, Vanoverberghe M, Neuprez A, Bruyere O, Reginster JY. Costeffectiveness of strontium ranelate for the prevention and treatment of osteoporosis. Expert Rev Pharmacoecon Outcomes Res. 2010;10(4):359-66. doi:10.1586/erp.10.53.

18. Hiligsmann M, Reginster JY. Cost effectiveness of denosumab compared with oral bisphosphonates in the treatment of post-menopausal osteoporotic women in Belgium. PharmacoEconomics. 2011;29(10):895-911. doi:10.2165/11539980-000000000-00000

19. Ethgen O, Standaert B. Population- versus cohort-based modelling approaches. PharmacoEconomics. 2012;30(3):171-81. doi:10.2165/11593050000000000-00000.

20. SPF Economie - Direction Générale Statistique et Information Economique. http://economie.fgov.be/fr/modules/publications/statistiques/economie/ prix_a_la_consommation_a_partir_de_1920_et_indice_sante_a_ partir_de_1994.jsp.

21. SPF Economie - Direction Générale Statistique et Information Economique. http://statbel.fgov.be/fr/modules/publications/statistiques/population/ downloads/population_au_1er_janvier_2014-2061.jsp.

22. Haentjens P, Magaziner J, Colon-Emeric CS, Vanderschueren D, Milisen K, Velkeniers B, et al. Meta-analysis: excess mortality after hip fracture among older women and men. Ann Intern Med. 2010;152(6):380-90. doi:10.7326/ 0003-4819-152-6-201003160-00008.

23. Hiligsmann $M$, Bruyere $O$, Roberfroid D, Dubois C, Parmentier $Y$, Carton J, et al. Trends in hip fracture incidence and in the prescription of antiosteoporosis medications during the same time period in Belgium (2000-2007). Arthritis Res. 2012;64(5):744-50. doi:10.1002/acr.21607.

24. Kanis JA, Johnell O, Oden A, Sembo I, Redlund-Johnell I, Dawson A, et al. Long-term risk of osteoporotic fracture in Malmo. Osteoporos Int. 2000;11(8):669-74.

25. Klotzbuecher CM, Ross PD, Landsman PB, Abbott 3rd TA, Berger M. Patients with prior fractures have an increased risk of future fractures: a summary of the literature and statistical synthesis. J Bone Miner Res. 2000;15(4):721-39. doi:10.1359/jbmr.2000.15.4.721.

26. Kanis JA, Johnell O, De Laet $C$, Johansson $H$, Oden A, Delmas P, et al. A meta-analysis of previous fracture and subsequent fracture risk. Bone. 2004;35(2):375-82. doi:10.1016/j.bone.2004.03.024 
27. Boonen S, Lips P, Bouillon R, Bischoff-Ferrari HA, Vanderschueren D, Haentjens P. Need for additional calcium to reduce the risk of hip fracture with vitamin d supplementation: evidence from a comparative metaanalysis of randomized controlled trials. J Clin Endocrinol Metab. 2007;92(4):1415-23. doi:10.1210/jc.2006-1404.

28. Tang BM, Eslick GD, Nowson C, Smith C, Bensoussan A. Use of calcium or calcium in combination with vitamin D supplementation to prevent fractures and bone loss in people aged 50 years and older: a meta-analysis. Lancet. 2007;370(9588):657-66. doi:10.1016/S0140-6736(07)61342-7.

29. Bischoff-Ferrari HA, Willett WC, Wong JB, Stuck AE, Staehelin HB, Orav EJ, et al. Prevention of nonvertebral fractures with oral vitamin $D$ and dose dependency: a meta-analysis of randomized controlled trials. Arch Intern Med. 2009;169(6):551-61. doi:10.1001/archinternmed.2008.600.

30. Cleemput I, van Wilder P, Huybrechts M, Vrijens F. Belgian methodological guidelines for pharmacoeconomic evaluations: toward standardization of drug reimbursement requests. Value Health. 2009;12(4):441-9. doi:10.1111/ j.1524-4733.2008.00469.x.

31. Autier P, Haentjens P, Bentin J, Baillon JM, Grivegnee AR, Closon MC, et al. Costs induced by hip fractures: a prospective controlled study in Belgium. Belgian Hip Fracture Study Group. Osteoporos Int. 2000;11(5):373-80.

32. Melton 3rd LJ, Gabriel SE, Crowson CS, Tosteson AN, Johnell O, Kanis JA. Cost-equivalence of different osteoporotic fractures. Osteoporos Int. 2003;14(5):383-8. doi:10.1007/s00198-003-1385-4.

33. Walensky RP, Ross EL, Kumarasamy N, Wood R, Noubary F, Paltiel AD, et al. Cost-effectiveness of HIV treatment as prevention in serodiscordant couples. N Engl J Med. 2013;369(18):1715-25. doi:10.1056/NEJMsa1214720.

34. Gomez JA, Lepetic A, Demarteau N. Health economic analysis of human papillomavirus vaccines in women of Chile: perspective of the health care payer using a Markov model. BMC Public Health. 2014;14:1222. doi:10.1186/ 1471-2458-14-1222.

35. Johnell O, Kanis JA. An estimate of the worldwide prevalence and disability associated with osteoporotic fractures. Osteoporos Int. 2006;17(12):1726-33. doi:10.1007/s00198-006-0172-4.

36. Hiligsmann M, Evers SM, Ben Sedrine W, Kanis JA, Ramaekers B, Reginster JY, et al. A systematic review of cost-effectiveness analyses of drugs for postmenopausal osteoporosis. PharmacoEconomics. 2015;33(3):205-24. doi:10.1007/s40273-014-0231-1.

37. Rodriguez Barrios JM, Perez Alcantara F, Crespo Palomo C, Gonzalez Garcia P, Anton De Las Heras E, Brosa Riestra M. The use of cost per life year gained as a measurement of cost-effectiveness in Spain: a systematic review of recent publications. Eur J Health Econ. 2012;13(6):723-40. doi:10.1007/ s10198-011-0326-y.

38. Azimi NA, Welch HG. The effectiveness of cost-effectiveness analysis in containing costs. J Gen Intern Med. 1998;13(10):664-9.

39. Laupacis A, Feeny D, Detsky AS, Tugwell PX. How attractive does a new technology have to be to warrant adoption and utilization? Tentative guidelines for using clinical and economic evaluations. CMAJ. 1992;146(4):473-81.

40. Owens DK. Interpretation of cost-effectiveness analyses. J Gen Intern Med. 1998;13(10):716-7.

41. World Health Organization (WHO). Choosing interventions that are cost effective. Available at http://www.who.int/choice/costs/CER_thresholds/en/ index.html. Accessed 25 Apr 2009.

42. Kanis JA, Johansson $H$, Oden A, De Laet C, Johnell O, Eisman JA, et al. A meta-analysis of milk intake and fracture risk: low utility for case finding. Osteoporos Int. 2005;16(7):799-804. doi:10.1007/s00198-004-1755-6.

43. Michaelsson K, Wolk A, Langenskiold S, Basu S, Warensjo Lemming E, Melhus $\mathrm{H}$, et al. Milk intake and risk of mortality and fractures in women and men: cohort studies. BMJ. 2014;349:g6015. doi:10.1136/bmj.g6015.

44. van den Berg P, van Haard PM, van den Bergh JP, Niesten DD, van der Elst M, Schweitzer DH. First quantification of calcium intake from calcium-dense dairy products in Dutch fracture patients (the Delft cohort study). Nutrients. 2014;6(6):2404-18. doi:10.3390/nu6062404.

45. Wlodarek D, Glabska D, Kolota A, Adamczyk P, Czekajlo A, Grzeszczak W, et al. Calcium intake and osteoporosis: the influence of calcium intake from dairy products on hip bone mineral density and fracture incidence - a population-based study in women over 55 years of age. Public Health Nutr. 2014;17(2):383-9. doi:10.1017/S1368980012005307.

46. Bischoff-Ferrari HA, Dawson-Hughes B, Baron JA, Kanis JA, Orav EJ, Staehelin HB, et al. Milk intake and risk of hip fracture in men and women: a meta-analysis of prospective cohort studies. J Bone Miner Res. 2011;26(4):833-9. doi:10.1002/jbmr.279.
47. Grey A, Bolland M. Web of industry, advocacy, and academia in the management of osteoporosis. BMJ. 2015;351:h3170. doi:10.1136/ bmj.h3170.

48. Bolland MJ, Grey A, Reid IR. Calcium supplements and cardiovascular risk in the Women's Health Initiative. Osteoporos Int. 2013;24(8):2371-2. doi:10.1007/s00198-013-2356-z.

49. Paik JM, Curhan GC, Sun Q, Rexrode KM, Manson JE, Rimm EB, et al. Calcium supplement intake and risk of cardiovascular disease in women. Osteoporos Int. 2014;25(8):2047-56. doi:10.1007/s00198-014-2732-3.

50. Kalkwarf HJ, Khoury JC, Lanphear BP. Milk intake during childhood and adolescence, adult bone density, and osteoporotic fractures in US women. Am J Clin Nutr. 2003;77(1):257-65.

51. Heaney RP. Dairy and bone health. J Am Coll Nutr. 2009;28 Suppl 1:82S-90S

52. Rizzoli R. Dairy products, yogurts, and bone health. Am J Clin Nutr. 2014;99(5 Suppl):1256S-62S. doi:10.3945/ajcn.113.073056.

53. Fernandez-Barres S, Martin N, Canela T, Garcia-Barco M, Basora J, Arija V et al. Dietary intake in the dependent elderly: evaluation of the risk of nutritional deficit. J Hum Nutr Diet 2015. doi:10.1111/jhn.12310

54. Lekkerkerker F, Kanis JA, Alsayed N, Bouvenot G, Burlet N, Cahall D, et al. Adherence to treatment of osteoporosis: a need for study. Osteoporos Int. 2007;18(10):1311-7. doi:10.1007/s00198-007-0410-4.

55. Prince RL, Devine A, Dhaliwal SS, Dick IM. Effects of calcium supplementation on clinical fracture and bone structure: results of a 5-year, double-blind, placebo-controlled trial in elderly women. Arch Intern Med. 2006;166(8):869-75. doi:10.1001/archinte.166.8.869.

56. Hiligsmann M, Boonen A, Rabenda V, Reginster JY. The importance of integrating medication adherence into pharmacoeconomic analyses: the example of osteoporosis. Expert Rev Pharmacoecon Outcomes Res. 2012;12(2):159-66. doi:10.1586/erp.12.8.

57. Chen P, Hu P, Xie D, Qin Y, Wang F, Wang H. Meta-analysis of vitamin D, calcium and the prevention of breast cancer. Breast Cancer Res Treat. 2010;121(2):469-77. doi:10.1007/s10549-009-0593-9.

58. Murphy N, Norat T, Ferrari P, Jenab M, Bueno-de-Mesquita B, Skeie G, et al. Consumption of dairy products and colorectal cancer in the European Prospective Investigation into Cancer and Nutrition (EPIC). PLoS One. 2013;8(9), e72715. doi:10.1371/journal.pone.0072715.

59. Bjelakovic G, Gluud LL, Nikolova D, Whitfield K, Wetterslev J, Simonetti RG, et al. Vitamin $D$ supplementation for prevention of mortality in adults. Cochrane Database Syst Rev. 2014;1:CD007470. doi:10.1002/ 14651858.CD007470.pub3.

\section{Submit your next manuscript to BioMed Central and take full advantage of:}

- Convenient online submission

- Thorough peer review

- No space constraints or color figure charges

- Immediate publication on acceptance

- Inclusion in PubMed, CAS, Scopus and Google Scholar

- Research which is freely available for redistribution

Submit your manuscript at www.biomedcentral.com/submit
C Biomed Central 